\section{Checkpoint inhibitors and arthritis}

It was with interest that we read the article by Belkhir et al in the recent Annals of Rheumatic Disease. The article described the first report of rheumatoid arthritis (RA) and polymyalgia rheumatica developing after the use of immune checkpoint inhibitors to treat a variety of cancers. We found the article interesting and informative but noted that in all of their 10 reported cases, the patients seroconverted from rheumatoid factor (RF) or cyclic citrullinated peptide antibody (CCP) negative to positive, supporting their claim that 'rheumatoid arthritis' may develop after immune checkpoint inhibitor treatment.

The report by Belkhir et al is in contrast to our experience managing 18 patients with musculoskeletal immune adverse events, subsequent to checkpoint inhibitor treatment. None of our patients seroconverted after treatment (manuscript in preparation) and none had clinical features suggestive of RA. In addition to the negative serology, MRI of affected joints failed to identify synovial hypertrophy to suggest the start of pannus formation. In one patient with hypophysitis who did develop autoantibodies (cytoplasmic anti-neutrophil cytoplasmic antibodies (cANCA); proteinase $3(\mathrm{PR} 3)>100 \mathrm{U})$, there was no clinical evidence of vasculitis. We find that the autoimmune toxicities differ from the 'classical' autoimmune entities known to each specialty, for example, the colitis is not ulcerative colitis or Crohn's; it is its own entity, with widely varying pathological findings between patients. Similarly with arthritis, there was no 'hallmark' pathological finding even though tenosynovitis featured highly. In accord with Belkhir, all of our patients responded well to non-steroidal anti-inflammatory drugs, low dose steroids and, in certain cases, methotrexate.

We cannot explain the different experience we have had with our patient group (France vs Australia). We wonder if there is a subgroup of patients that do seroconvert and are curious to find what the cause may be to account for such dissimilarities. We can only speculate on possibilities such as geography, ethnicity, diet or smoking. For instance, with regards to smoking, we have data showing that nicotine can influence $\mathrm{T}$ cell receptor function that consequently could influence antibody formation (manuscript in preparation). Other published modes of action of nicotine include upregulation of peptidylarginine deiminase that enhances the production of CCP. ${ }^{2}$ Under normal circumstances, the detection of autoimmune clones by the immune system leads to their suppression by regulatory suppressor immune cells that prevent the progression to disease. In the case of checkpoint inhibitors, this regulatory check point is lost and cells stimulated by cigarette smoke (nicotine) lead to a heightened production of RF or anti-CCP. Smoking in France is much more prevalent than in Australia. It would be interesting to know what percentage of the patients in the above study were smokers.

The reporting of musculoskeletal immune adverse effects due to checkpoint inhibitors is in its infancy. We believe it is important that the experience that groups in different countries are finding needs to be reported.

Thank you for this thought-provoking article.

Nicholas Manolios, ${ }^{1,2}$ Leslie Schrieber ${ }^{1,3}$

${ }^{1}$ Faculty of Medicine, University of Sydney, Sydney, New South Wales, Australia ${ }^{2}$ Department of Rheumatology, Westmead Hospital, Sydney, New South Wales, Australia

${ }^{3}$ Department of Rheumatology, Royal North Shore Hospital, Sydney, New South Wales, Australia

Correspondence to Professor Nicholas Manolios, University of Sydney, Sydney, NSW 2006, Australia; nicholas.manolios@sydney.edu.au

Contributors Both authors made substantial contributions to the conception or design of the letter and important intellectual content.

Funding The authors have not declared a specific grant for this research from any funding agency in the public, commercial or not-for-profit sectors.

Competing interests None declared.

Patient consent Not required.

Provenance and peer review Not commissioned; internally peer reviewed.

(c) Article author(s) (or their employer(s) unless otherwise stated in the text of the article) 2019. All rights reserved. No commercial use is permitted unless otherwise expressly granted.

$$
\text { Check for updates }
$$

To cite Manolios N, Schrieber L. Ann Rheum Dis 2019;78:e58.

Received 14 March 2018

Accepted 16 March 2018

Published Online First 23 March 2018

Ann Rheum Dis 2019;78:e58. doi:10.1136/annrheumdis-2018-213415

\section{REFERENCES}

1 Belkhir R, Burel SL, Dunogeant L, et al. Rheumatoid arthritis and polymyalgia rheumatica occurring after immune checkpoint inhibitor treatment. Ann Rheum Dis 2017;76:1747-50.

2 Makrygiannakis D, Hermansson M, Ulfgren AK, et al. Smoking increases peptidylarginine deiminase 2 enzyme expression in human lungs and increases citrullination in BAL cells. Ann Rheum Dis 2008;67:1488-92. 